\title{
Critical Pedagogy in the University: Can a lecture be critical pedagogy?
}

Interest in student-centred learning and pedagogy in the university continues to grow (Lea, Stephenson \& Troy, 2003), especially with more recent changes in HE policy which have positioned students as consumers of a product (O'Neill \& McMahon, 2005). The white paper Students at the Heart of the System (2011), for example, encourages universities to "create a learning community where engagement of students is encouraged, their feedback valued, and complaints resolved transparently" (p. 33). Although I agree that student-centred approaches can offer an opportunity to empower students by putting student engagement and activity at the centre of learning, it seems that the term is being co-opted by policy makers and education development centres as a way to satisfy students. At the same time, however, university educators are being asked to deliver courses designed for 20 students to a class of 60, without any apparent regard for the effect large class sizes have on pedagogy, student engagement, and effective learning. Despite being encouraged to implement student-centred approaches to teaching by their universities, the lack of resources, including staff time dedicated to teaching rather than research, is seen as a barrier to actually implementing student-centred learning approaches in the university classroom (Lea, Stephenson \& Troy, 2003; O’Neill \& McMahon, 2005). Further, studentcentred learning is often featured in University policy or guidelines, "but this has not necessarily transferred into practice" (O'Neill \& McMahon, 2005), meaning that that students might have expectations about student-centred learning that are not being met. This is not a recent development. Barnett (1990) argued 28 years ago that teachers in higher education must pay attention to the expectations and perceptions of their students because such students could simply study elsewhere if they did not "value their learning experience" (p. 153). This pressure to teach in a way that meets the expectations of students is compounded by the increasing importance placed on student satisfaction, as well as an increase in student numbers which affect the kind of pedagogy that can be implemented. These constraints often lead to a more monological, didactic approach to teaching commonly known as the lecture.

The lecture has been criticised by many educators over the years, perhaps most notably by Paulo Freire (1970), commonly recognised as the founder of critical pedagogy, who described the process of "banking education". This process is often associated with the traditional lecture, in which the 'expert' stands at the front of the class and delivers a monologue on a particular topic, often presenting the information as immutable facts, with little to no participation from students. In Freire's depiction of the banking model of education, the teacher makes a deposit of knowledge into the account of students, without requiring any processing or changing of this information on the part of the student. Freire considered education a "tool for social and cultural emancipation," something which could be achieved through portraying and practicing education as a political and pedagogical project in which dialogue, democratization of teacher-student relationships, co-construction of the curriculum, and making learning relevant to the learner are valued (Schugurensky, 2014, p. 39). 
Looking at higher education from a Freirean perspective, one might not consider the lecture to fulfil any of the aims of critical pedagogy, or of a transformative higher education more generally. However, in considering Webster's (2015) article In Defence of the Lecture, in which the common understanding of Freire's banking model is challenged, the idea that a lecture might serve a critical pedagogical approach can be considered. Reflecting on the data collected observing and interviewing critical pedagogues in English universities, I also started to question whether the perhaps emphasis should be put on the content rather than the way it is transmitted. However, while this highlights the inter-connected relationship between curriculum and pedagogy, ultimately it points to two different ideas: critical pedagogy, with a focus on the method, and a critical curriculum, which focuses more on the content. Although one could argue there is no critical pedagogy without a critical curriculum, it does seem that a critical curriculum without critical pedagogy is possible and might be prevalent in higher education. Examples of the latter could be a lecture which presents content that is critical of power in society yet does not enact a critical approach to teaching by challenging power dynamics in the classroom. By exploring these distinctions, a more coherent understanding of critical pedagogy might be possible.

Throughout my research on critical pedagogy in the university, in which I observe and interview self-identifying critical pedagogues (SICPs), I have experienced a range of different teaching approaches which fall on a spectrum which ranges from completely democratic to more traditional, didactic methods. Yet all of these SICPs claimed to be involved in critical pedagogy - which is itself hard to define or pin down. This range of pedagogical approaches is akin to Breunig's (2009) article in which she critically reflects on her own pedagogical practice and how it relates to her critical beliefs. In this study, Breunig (2009) interviews other SICPs to see how their practice corresponds with their pedagogical values. Her results indicate that there may be a disconnect between theory and practice, which occurs when pedagogical beliefs are not implemented. A similar idea is explored by Aronowitz \& Giorux (1985) in their conceptualization of educators as intellectuals involved in a pedagogical project in which educators can be critical or accommodating of hegemonic ideologies, as well as actively working for or against these ideologies. The practice of these 'educatorintellectuals' or SICPs might be explained in a number of ways, which also apply to those who participated in my study: (1) self-identifying critical pedagogues do not really know what critical pedagogy is in practice, (2) I do not know what critical pedagogy looks like (or should look like), (3) putting critical pedagogy into practice is not possible in the current HE system, or (4) critical pedagogy is not about their practice, but more about what they are teaching (including but also beyond the curriculum) and how they go about presenting it (e.g. how they present knowledge as fixed or changeable, context dependent, etc.). This fourth possibility is what I will be exploring in this paper by bringing together Webster's (2015) defence of the lecture, Aronowitz \& Giroux's (1985) paper Radical Education and Transformative Intellectuals, and my own research into SICPs in English HE.

Reconsidering the critical and transformative potential of the lecture is important because critical educators are increasingly being pushed to the margins and their academic freedom to teach as they want is being supressed by large class sizes and fewer contact hours with students. Perhaps if we can change the way we approach the lecture, we can make it a more transformative experience for students even if they are in a class of 150 students. Maybe, by looking at how SICPs are coping with the effects of marketisation of HE so far, we 
can identify new ways forward that can still maintain a critical approach to teaching through critical curriculum choices, and by questioning the knowledge that is presented in the lecture-whether it comes from lecturers or from other 'experts'.

\section{Research Design}

In this paper I will be focusing on the first three participants of my $\mathrm{PhD}$ research, whom I observed and interviewed in the 2016-2017 academic year. These participants were the first three to be interviewed out of a larger sample of 11 and offer a starting point for discussion for this paper. Because an interpretivist approach is used in this study I do not think the small sample is an issue, especially since I am not trying to make generalizations, and the data is used to explore two theories through concrete examples. Snowball sampling was used to find and approach SICPs in English universities for the larger sample, which consisted of 11 participants for the interviews and 8 for observation (some could not be observed for practical reasons). Two of the participants teach at a Russell Group university in London, while one teaches at a Red Brick university in the northeast. I used participant observations to better understand the practice of each educator, participating in at least two of their classes, and then interviewed them after the second observation. This interview was a chance for both me and the SICP to reflect on our experience in the class and discuss how they had put their critical beliefs into practice in the classroom. Both the participant observations and the interviews were semi-structured, in that there were not pre-identified practices that I was trying to find or questions that had to be answered aside from a broad research interest concerning the translation of critical pedagogical values and beliefs into pedagogical practice.

I began each interview by reflecting on my experience in the SICP's classes and the questions came out of this experience. In an effort to mediate the power dynamic present in the interview and observation, participants were asked in advance to identify any topics they wanted to discuss in the interview. This was done in an attempt to make the research method and process more 'critical,' in that I constantly reflected on how I collected data, treated participants, and the reasons for doing research in a certain way. There were few ethical concerns with the design, which were mainly focused on anonymity and confidentiality. Teachers and students were informed about the participant observations beforehand through information sheets, which outlined the purpose and process of the research, as well as the ethical concerns and how they would be addressed. Lecturers were guaranteed anonymity and confidentiality, so they would feel more comfortable openly reflecting on their experiences teaching within the university.

\section{Scope and Limitations of the Study}

The aim of my research more generally is to better understand the beliefs and practices of SICPs and the factors that influence their practice. The scope of this paper is narrower-it aims to explore whether the lecture (or a transmission style of instruction) can be critical pedagogy by looking at data from my research through the ideas of Webster (2015) on lectures and Aronowitz \& Giroux's (1985) work on transformative and critical educators. Due to the limited space of the paper, there are several ideas that must be taken for granted: (1) it is assumed that using critical pedagogy in higher education is desirable despite the fact that it has its roots in a different context, (2) on some level it is assumed that education should be a critical experience, and (3) it is assumed that most lectures do 
not offer a critical educational experience for students empowering them to challenge knowledge we take for granted as well as the power dynamics of the classroom, and society more generally. Of course, there are some limitations to the study, which centre mainly around the sample and the methodology. The small sample size is a limitation even though generalizations are not being made about all SICPs or all university lecturers. Having more examples to connect to the concepts presented by Webster and Aronowitz \& Giorux would be helpful for readers and would demonstrate more of either a consensus or variety of experiences. There might also be a limitation around the way the sample was selectedsnowball sampling is commonly used in situations where the population is hard to access. Contact was first made at a critical pedagogies conference, and then there was a referral chain that I chased up via emails to recommended participants. However, of the twenty people contacted, several responded saying they were not critical pedagogues, meaning that the people that were doing the referring may have misidentified their peers. Following on from this, it is possible that some of the participants may not really identify as critical pedagogues, but they wanted to be helpful, or they were interested in learning more about critical pedagogical practice. However, due to the open nature of my research questions, I am not sure this is a major limitation of the sampling method, especially in the case of this paper which is more about exploring theory through a small set of examples.

In terms of the methodology, in an attempt to share power with participants, the interviews were left un-structured, and participants were able to lead discussions in whatever way they thought was relevant to the observations and to the conversation. Again, this limits the ability to make generalisations and comparisons across participants, but as I was trying to explore their perceptions about critical pedagogy and practice more generally in order to thematically analyse these perceptions, I don't think this is a serious concern. Of course, curriculum, pedagogy, educators and students vary from institution to institution, and even within institutions in different departments or disciplines. The picture, therefore, that I am painting of SICPs in English higher education is based on my own experience and the perceptions of those that I have interviewed and is thus not representative of all HE educators in the UK. Since I have chosen to focus on those that use a particular approach, I do not think this is a major limitation to the study, and in fact, coming from a critical approach I try to avoid attempts to make sweeping generalisations about all educators or even all SICPS. Each of these educators operates within an institution and a system that influences what they are able to do, and so context is very important, as well as the differences between the contexts. Therefore, I will begin by introducing the three different SICPs and then I will explore the data from the interviews thematically, and then through ideas presented by Webster (2015) and Aronowitz \& Giroux (1985).

\section{Observation Data}

\section{Case 1: Arthur}

Arthur teaches education and international development at a Russell Group university in London. I observed two of his classes in the autumn of 2016, one he taught by himself and the other he co-taught with an educator that specializes in post-colonialism. The class was so large that two classrooms had to be joined together to fit all the students. There were so many students crammed into this space that some didn't have desks, and the students at the back of the room were so far away a microphone had to be employed so that they could 
hear the teacher. A second roving microphone was passed around so that students who had questions could also be heard. In the first session I observed, Arthur began by reporting some of the suggestions that students had put forward on an online learning platform to address the large class size issue. From the choices presented, the students chose how the class would function going forward. The sessions I observed followed similar schedules: about an hour and a half of lecture with questions and some group discussions throughout, followed by a 'breakout' session where students were split into groups of about 10, each with a facilitator (lecturer or PhD student), which discussed the content covered in the class as well as some questions that were posed by the lecturer. The two sessions I observed focused on post-colonialism, international development and education for social transformation. These topics were explored using real life examples from the research of the lecturers and sometimes from the students, drawing on critical pedagogy, poststructural, and post-colonial theories to explore alternative methods of education and their effects in various contexts.

\section{Case 2: Louisa}

Louisa teaches a course on radical education at a Russell Group university in London. I observed three sessions of her third-year bachelor's module in the spring of 2017. This option module was quite small, with an average of 10-15 students showing up each session, although 28 were enrolled. The class was a combination of lecture and discussion, with students expected to read assigned reading before class. There was also a seminar that met at another time and was led by a PhD student of Louisa's. Like Arthur's class, the content of this module was relatively 'critical' in that it focused on alternatives to mainstream schooling. The three classes I attended were about historical social movements in education, critical pedagogy, and education and social change. The first class I attended was the introduction to the module, and in this session, Louisa began by telling the students how passionate she was about radical education and social change. She also said she didn't want to lecture all the time and instead wanted there to be discussion around what radical education is, which was the main question to be explored throughout the course. The class began by unpicking the word 'radical', with questions around how the word is used and what it implies. Through several group exercises, we developed a discussion around the various meanings of 'radical', as well as some other related terms like 'fundamental', 'indoctrination', and 'hegemony'. Louisa went on to explore social movements that seemed quite radical at the time (for example, women's rights, or the abolition of slavery), movements we take for granted now as being perfectly just and normal. Louisa tried to get students engaged by asking questions but was for the most part met with silence. The second class was on Paulo Freire and other educational movements from South America. We started the class with a discussion of Chapter Two of Pedagogy of the Oppressed in groups, however due to lack of engagement, the class gradually turned into a lecture. The third class was about historical social movements, such as the Chartists, and more current movements such as Black Lives Matter. Through questions and group discussions Louisa encouraged us to think about how social action itself can be educative.

\section{Case 3: Chris}

Chris teaches several different classes relating to education at a redbrick university in the northeast of England. I attended two different classes-one which was masters level and one that was bachelor's level in the spring of 2017. Typically, I attend more than one session 
of the same class because then I can get a better feel for what usually happens in the class, but Chris mentioned that due to class sizes and the different levels of the courses, she often uses different approaches in the classes. The first class I attended was a bachelors module on democratic decision making, which had 38 students in attendance. This class was extremely active, because, rather than simply teaching the class about democratic decision making, Chris allowed students to undertake the democratic process in practice. The class started with a warm-up discussion that got students thinking about self-governance and democratic decision making. We then explored how they were related to democratic schools and how we could get young people more involved in decision making in schools. Then, we participated in three activities to explore three different methods of democratic decision making: representative, direct democracy, and sociocratic. We then discussed how we thought these decision-making methods could be used in mainstream schools.

The second class I observed was a master's level class on inclusive and special education, which had 17 students. The module was co-taught with another lecturer from a different discipline, which Chris felt brought an interesting dynamic to the class. We had been asked to read an article written by Chris before the class, which she then told us more about through a presentation. Her plan was to tell us about her research and then talk about how they could apply it to other settings. Because this is a master's level class, more of the students are already teaching or have taught at some point, so there is an attempt to connect the theories discussed in the class to their professional practice. Since the class would be slightly different than normal, in that it was a lecture, she gave us post-it notes to write questions on in case we had a thought during the lecture. In her lecture, she talked about her research comparing democratic schools in Europe and the UK, and the connection between pedagogy and space. After the lecture we had 15 minutes of questions, which mainly focused on the context-specific nature of making changes at schools and how we can learn from cases in different contexts. We then broke into groups and had a 30-minute discussion about how we could apply these ideas to a particular context (different levels of education) and what would and wouldn't work. After reporting back to the group and discussing the different challenges, we took the final five minutes of the class to reflect on how what we learned today could also affect inclusion.

\section{Interview Data}

In this section I will draw on interview data from my research to further explore the cases outlined above by looking at pedagogical decisions and what influences them.

\section{Designing courses}

Arthur, Louisa, and Chris all talked about the design of their modules at some point in the interview. For Arthur, this centred around the improvisation that took place in his class due to the unexpected large number of students who enrolled that term. Unsurprisingly, Arthur pointed out that the pedagogical approach used with 20-30 students had to vary from a class of more than one-hundred students. Ordinarily there would be no need for a seminar or break-out session because this would be intertwined, and the lecture would be broken up by discussions and activities to get the students more involved in the class. In an effort to address these issues, the students were consulted to come up with ideas for making the class more participatory and more functional for such a large number of students. A lot of thought seemed to go into creating a space where students felt comfortable sharing ideas 
and asking questions. This was also a result of the content of the class and the kind of people interested in international development, as well as the diversity of the cohort. According to Arthur, all of these factors contributed to a more social atmosphere. The way the course is set up encourages the students to make connections between the theories they are learning about and their own context.

When speaking of the design of her BA module, Louisa highlighted the differences between $B A$ and MA classes. In her experience, teaching MA classes was much easier because students were more mature, came prepared to discuss ideas, had more experience to draw on, and typically had more interest in the course. Whereas, on the BA modules she has taught on thus far, she felt more of an obligation to teach content:

I really feel like my job is to kind of, um, make them aware of things that they're not aware of. And break down material for them that might be difficult, in a way that is accessible and makes sense to them. And that's a very difficult kind of thing. So I'm not sure if I can do that in a way that also leaves room for actually hearing their voices (Louisa, interview)

She also expressed that sometimes the lack of knowledge on certain topics made critique difficult. How can she expect students to be critical of concepts like colonialism or race when they do not understand what they are? In her opinion, a lot of time was needed to teach students material that would help them later on in their degree or on the course, which meant there wasn't as much time for open discussion about the reading or the social movements being discussed.

Chris talked about the design of her BA module, which had changed and developed over time. The module was originally written for her by the director, so the learning outcomes and the shell of the module were already decided. But as she taught the class over the years it changed and became much more experiential, whereas it was designed to be more theoretical (and possibly more suited to a lecture). Constantly reflecting on what works best for the class has motivated most of the changes: content that could be merged with another session or the removal of a group presentation that wasn't supporting learning. Although Chris tries to let students get involved in making decisions about the course, like what to do with extra time and support sessions, or choosing their essay titles, many students do not respond well to having the freedom to make these decisions. In contrast, on the MA module she feels the course is typically more led by student discussions and questions and engagement with theory, and thus more praxis oriented.

\section{Assessment in university}

Despite doing what they can to make the large class more interactive, Arthur pointed out that they are still limited by structural and systemic constraints of the university, particularly in relation to assessment. A student of his pointed out that the idea of assessment in university narrows what is seen as an acceptable answer. This clashes with the "ecology of knowledges" view that is promoted on the course, in which different epistemologies from different cultural groups are equally valued. This also highlights how assessment can affect the content of the course, especially in cases where educators are working on modules that they have not designed or where they have little control over curriculum and assessment. In many senses, Arthur feels that sometimes it is a challenge to 'practice what you preach' when you work within a system with a very strict set of criteria or parameters. Louisa also 
voiced her concerns with assessment and how it affects her ability to be a real critical pedagogue:

I mean that is a problem, right? When you're trying to do something critical and radical but you're in this framework that is very, very standard and traditional, and you're awarding grades... And of course, that undermines my ability to be a real critical pedagogue. Because $I^{\prime} m$ in the role of someone with huge authority in the sense that I' $m$ the one who decides what grade they get, and that could be the difference between, you know, a first-class degree and a second class or failing the course. So...it's a bit artificial to think we can create this little space of critical pedagogy... (Louisa, interview)

Potentially in an effort to give students more power over assessment, Chris asks students to choose their own essay question and title. However, Chris found that even this small amount of freedom was daunting for some students, who would rather have a set question to answer. Plus, there is also a tension here-even though the students have the power to choose their question, it is still assessed by means of a standardised framework. Chris pointed out this means there is even more pressure put on the student because not only do they have to write a good essay, they also have to pick an acceptable question. But how can we avoid the authority given to educators through assessment in a system that is totally reliant on grades and measurement?

\section{Class Sizes}

The issue of increasing class sizes was something that came up frequently in Arthur and Chris's interviews. Some of the problems that Arthur encountered have already been addressed, but there were other issues around participation that seemed to go beyond pedagogical approaches. The larger the class size, the less likely students seem to be willing to participate, especially in cases where a microphone is involved. First of all, since students had to use a microphone to speak, part of the group remained silent, but this also adds pressure to those using the microphone meaning others may not contribute. But also, in Arthur's opinion, the larger the group the fewer students that are actively engaged. In fact, the students on Arthur's course have been quite critical of the class size and have complained to the university:

And I'm afraid the university treats students very badly, for the most part and, because there is a kind of income maximization strategy and you know, if you can get away with having large numbers as an institution... But the model of course we have here is for a very low number of contact hours and taught classes. ... So for those few hours that they're in class they need to have a really intense pedagogical experience and you can't have that with those huge groups. (Arthur, interview)

Chris was equally critical of increasing class sizes at her university, because of the effect on the personal rapport she can build with students, which in turn affects learning.

I really can't stress this enough; the size of the group massively effects the learning. And, um, this year it's been really difficult. Some of what you saw in that group...you know, I was quite pleased with the session that you saw actually, but engaging some students when there are so many in a group is difficult, and me being able to even have a sense of them all as individuals, I mean I struggle with their names, and that's the most basic thing around having an individual connection with people. (Chris, interview) 
The large class sizes, in Chris's experience, tend to be less interactive because students struggle to speak out and get involved in discussions, and she struggles to tailor the content to be more relevant to students. At her university courses do not run unless there are at least 15 students, but class sizes of 50 or 60 , and even more in the sciences, are encouraged. Chris thinks this is a real problem because students get lost, and "lecturers are going to often really struggle to do anything apart from stand at the front and talk" (Chris, interview).

\section{Autonomous, Critical Learners}

Another theme that came out of the interviews was the challenge of empowering students to be more critical and autonomous as learners, something that was affected by all three areas that have been mentioned so far: pedagogy, assessment, and class size. Louisa mentioned the struggle to get students engaged in critical thought and debates about ideas when they had not been previously exposed to this kind of learning. She felt that students seem to come to university wanting someone to tell them what to think rather than expressing their own views or being critical of what the lecturer tells them. This was echoed by Chris, who felt like students were coming to university expecting a certain kind of experience, one that was very prescribed and traditional. Although she wanted to do things differently in her classes, sometimes she felt like students might actually be at a disadvantage if they were exposed to a democratic and critical classroom, and then had to go back to a more traditional class. Arthur, on the other hand, was more optimistic about students' ability to change as a result of the classes in his programme. He felt that students were often coming from backgrounds that did not encourage critique of ideas in education, and yet they were leaving the course with a more critical perspective. All three SICPs used group discussions, challenging questions, and examples from different contexts to expose students to different ways of thinking about education. Again, this highlights the dynamic between critical pedagogy and a critical curriculum - teaching critical content seems to be easier than teaching in a critical way in the current context, an idea that was echoed by Louisa:

But in terms of the actual pedagogical approaches and methods, I think there are problems with trying to make [critical pedagogy] work in a context like this, where you're so constrained by the structures. By, you know, the expectations of the students, of the other teachers. I mean, but I do...I do think that criticality has to be at the heart of what we do. (Louisa, interview)

\section{Is there Space for Critical Pedagogy in the University?}

Despite a general push toward more student-centred pedagogy, it seems that educators who identify as critical pedagogues seem to struggle to put their beliefs into practice within the current system, as Breunig (2009) suggested. This is especially the case in increasingly large classes, where they are asked to teach a class meant for 20 to a class of 60 students or more. All three participants voiced their concerns about not practising what they preached, with Chris going so far as to say she doesn't think she can call herself a critical pedagogue:

I'm not sure that I am a self-identifying critical pedagogue, in that way. Because I might selfidentify as, you know, aligning myself with those values and aspiring to work in that way, but actually I think that within a university, if I was to say that I am a critical pedagogue within 
my university, I'm setting myself up to fail because I actually think that is quite impossible. (Chris, interview)

However, there was some hope-both Arthur and Chris were optimistic about small scale changes going on in the margins of the university. For example, when asked whether he thought a more Freirean approach to higher education would ever work on a large scale, Arthur said probably not-but that isn't an issue:

... I think it's really important that things happen at a small scale. And that we talk about those things. So, some of my research is about looking at really interesting, alternative educational spaces that are really tiny and sort of forgotten or on the fringes of things, but nevertheless give us a fascinating account of what might be possible. (Arthur, interview)

Chris also expressed her belief that although being a critical pedagogue in the university system is difficult because of the many constraints and boundaries, having these boundaries lets her know how far she can push things. As long as students are passing the class and she is getting good ratings on the student feedback sheets, she can keep pushing the boundaries. But, like Arthur, she thinks it is important to encourage other people to do the same-to tell them that they can push things further.

\section{In Defence of the Lecture}

Looking at the data from the three cases described above, as well as other data not discussed here, it appears that the majority of SICPs are using lecturing as their main method of instruction. Of course, not every lecture is created equal, and some have content that is more critical, or involve questions and discussions that offer opportunities for the students to be more active and engaged. But does that make it critical pedagogy? Can a lecture ever be critical pedagogy? Webster's (2015) In Defence of the Lecture offers a challenge to those who consider the lecture to be an obsolete way of teaching in higher education. By arguing that a lecture is not always a monologue, and that it is not always a passive experience for students, he shows that, in fact, there are opportunities for disruption and transformation using the lecture format. Taking a deeper look at Freire's critique of the banking model of education, Webster points out that perhaps Freire is referring to a certain kind of lecturing or teaching that presents a certain kind of information. Freire refers to a narration sickness which occurs when "the teacher talks about reality as if it were motionless, static, compartmentalized, and predictable. Or else he expounds on a topic completely alien to the existential experience of the students" (Freire, 1970, p. 52). In this excerpt from Pedagogy of the Oppressed, it is important to note that Freire focuses on the kind of information or knowledge that is being shared with the students, the way it portrays the nature of knowledge as unchanging, and therefore not up for debate, and separate from human experience, rather than the pedagogy used to present it. To continue with the banking metaphor, Barnett (1994) points out that what is missing from this 'transaction' is a change in the student, or even the knowledge being transformed in the mind of the student (p. 42). In this sense, information is learned or memorized but not understood. However, this can happen in any method of teaching, not just in the lecture, suggesting that perhaps how knowledge is portrayed or thought of is more important than the method used to deliver it (Webster, 2015). For example, when reading an article for a seminar, students can read it and accept it as truth or fact without engaging 
with and critiquing it (or even understanding it). The same can be said of engaging in collaborative learning with your peers. In all of these cases, students are thinking-just maybe not very well or actively (Webster, 2015).

Another aspect of all methods of instruction that Webster highlights in association with the banking model is the tendency for research and ideas being presented to students as finished products, without all the thinking, work and mistakes that go into them. At least the lecture, according to Webster (2015), gives the opportunity for educators to display their thought processes, and can be an opportunity for students to learn how to approach problems and topics that are open to challenge. Displaying thought processes also reiterates to students that knowledge is not wholly objective, but instead something with a human element that can change and be challenged by others (Barnett, 1990). The description and justification that can come along with explaining a thought process also shows students that all knowledge is influenced by ideology and therefore is not neutral-it is being communicated by someone with either an implicit or explicit agenda in mind. Helping students grasp this is a good way to teach them to always have their critical awareness "turned on" (Webster, 2015). This would put students in a position to listen to a lecture that doesn't involve receiving the 'knowledge deposit' passively without challenging and critiquing what the teacher is saying, and thus, potentially avoiding Freire's concerns about the banking model of education. However, although this way of presenting the content of the course might show students that knowledge can be challenged, it avoids challenging the power dynamics in the classroom or lecture hall, a key aspect of critical pedagogy and a Freirean approach to education. Standing at the front of the class lecturing not only tells the students that the teacher is an expert and someone to be listened to, it also ignores the knowledge and experiences that the students bring with them to the class. This further separates the teacher and student, reinforcing a hierarchical relationship between the two.

Webster (2015) attempts to get around these limits of the lecture by calling for the lecture as a pedagogy of interruption. Looking at the unique features of the lecture that Webster has outlined through the lens of Biesta's (2010) pedagogy of interruption helps us see how lecturing could be a transformative experience for students, as it could provide an "encounter that might interrupt 'normal' ways of being and might provoke a responsive and responsible response" (p. 90). Biesta (2010) sees the purpose of education as helping students to "come into presence" through developing subjectivity in order to become more human, but without a predefined idea of what this means (p. 80). Subjectivity or "subjectification" is developed through encountering the Other and interrupting normal ways of being and seeing the world-this is a process that is ongoing and sporadic and naturally involves risk (Biesta, 2010). A pedagogy of interruption has to leave things open for interruption to occur, and is "a pedagogy committed to the possibility of interruption and perhaps also a pedagogy that itself will interrupt" (ibid, p. 91). However, Biesta's (2010) pedagogy of interruption could go further by interrupting ways of learning and ways of being in the classroom through critical pedagogy. This could be done through various methods, such as asking the students to give a presentation or lecture to other students, or negotiating the curriculum and acknowledging the expertise of students.

\section{What Makes Critical Pedagogy Critical?}


Even after reading Webster's (2015) defence of the lecture, I am still hesitant that a lecture could ever be critical pedagogy. However, it offers us some interesting ideas about how to get to the root of what critical pedagogy might look like in the university-by eliminating what isn't critical pedagogy perhaps we can better understand what is. To help explore this question further, I turned to Aronowitz \& Giroux's (1985) paper Radical Educators and Transformative Intellectuals.

In their paper, Aronowitz and Giroux (1985) identified four kinds of intellectuals: transformative, critical, accommodating, and hegemonic. At the heart of their project was to envisage educators as intellectuals in order to highlight the idea that all human action involves thinking and reflection, and that all education is political and ideological. Although Aronowitz and Giroux (1985) admit that these are oversimplified and idealized characterizations of educators and are theoretical constructs, their categories are helpful because they highlight the relationship between ideology, social practice, and education. They also draw attention to one of the key aims of critical pedagogy, which is to put theory into action for the purposes of social justice. Transformative intellectuals, therefore, strive to make the "pedagogical more political and the political more pedagogic" (Aronowitz \& Giroux, p. 56), which they accomplish by problematizing knowledge and modelling reflection and self-critique for students. Transformative intellectuals also make learning relevant to students so that they can "see themselves as social actors with... opportunities to engage in reflexive understanding of their own situation within the system of social relations" (Aronowitz \& Giroux, p. 56). Critical intellectuals, on the other hand, are critical of the social situation and the inequality of the status quo yet remain apolitical or removed from social action in part to maintain distance from that which they study. According to Aronowitz and Giroux (1985), accommodating intellectuals generally perpetuate the status quo, but often without realizing that they are doing so. Hegemonic intellectuals, on the other hand, willingly and consciously perpetuate the status quo that typically benefits them and the dominant 'ruling' class they associate with.

The purpose of using Aronowitz \& Giroux's framework is not to pass judgment or categorise people, rather to use their conceptualisations of educators as intellectuals to better understand the practice of SICPS. Would the three SICPs involved in my study, according to Aronowitz \& Giorux, be transformative or critical intellectuals? And, perhaps more importantly, would Aronowitz and Giroux consider a both transformative and critical intellectuals to be engaged in critical pedagogy? According to Aronowotz \& Giroux (1985), transformative intellectuals make the political more pedagogical by "utilizing forms of pedagogy which treat students as agents, problematizes knowledge, and makes knowledge meaningful so as to make it critical in order to make it emancipatory" (p. 56). Although they do not explicitly discuss the pedagogy of critical intellectuals in their paper, Aronowitz \& Giroux do claim that critical intellectuals "do not see themselves as connected either to a specific social formation or as performing a general social function that is expressively political in nature" (p. 57). Therefore, it seems that a critical intellectual would most likely not be engaged in critical pedagogical practice if they do not aim to be involved in making the "pedagogical more political" (p. 56).

The participants in my study all identified as critical pedagogues, and yet despite their critical beliefs, their method of instruction in the classroom was mostly in line with 
traditional methods of teaching (i.e., lecturing). However, Aronowitz \& Giroux's reasons for the incongruity between values and practice was for educators to distance themselves from their object of study or to resist the political and ideological nature of education. In the case of my participants, and as you can see from the data presented, this does not appear to be the reason for their inability to implement what might generally be thought of as critical pedagogy. In their case, it seems that the system they work within makes it difficult for them to put their critical beliefs about pedagogy into practice in the way they would like. Large class sizes, restrictive assessment practices, and students accustomed to the banking model of education make it almost impossible for spaces in which critical pedagogy can work. But there are still spaces-and just because it is hard does not mean we should stop trying or looking for those spaces. As Arthur said, small scale projects can offer hopeful examples to others who might want to use these approaches. Chris believes that by pushing at the boundaries of what universities find acceptable we can make more room for critical pedagogy, and we can spread the news to colleagues about how they too can push the boundaries.

\section{Discussion and suggestions}

The four intellectual classifications presented by Aronowitz \& Giroux (1985) highlight the ideological and political nature of education, as all of them either fight against or perpetuate the status quo, whether they are aware of this or not. This ties in with Webster's (2015) assertion that it is essential that students understand that knowledge is not unchangeable, and that ideology is always present in what they are learning. According to Webster, the human element of lecturing makes this clearer than reading from a paper or viewing PowerPoint slides online. A seminar could do this even more by encouraging discussion between students from different countries or backgrounds, or by engaging in problembased learning or research, moving toward a pedagogy of interruption (Biesta, 2010). Looking at the observations and interviews with critical pedagogues, one can see how their lectures made the "pedagogical more political and the political more pedagogic" (Aronowitz \& Giroux, 1985, p. 56) by challenging ways of thinking about education, raising awareness about social and political change through activism, explaining ways of thinking and doing research, challenging the hierarchy in the classroom, and allowing room for disagreement and interruption. All of these practices may help mediate the constraints of large class sizes and assessment regulations, but if they could, most of the SICPs would likely have taught their classes in a different way. Perhaps there is a better way to lecture, if one has to, which can make it more critical-by challenging ideas, presenting conflicting perspectives, portraying knowledge as changeable and context specific, and by encouraging students to engage in critical dialogues with their peers - but it still isn't critical pedagogy. Instead, we should turn to more active learning approaches, like Freire's problem-posing education or staff-student partnership, which help to challenge the power imbalance between staff and students, putting critical ideas about power and knowledge into practice in the classroom. Perhaps by challenging the dynamic in the University classroom or lecture hall, we can leave space for "students to invest something of themselves in what it is they say or do" (Barnett, 1990, p. 154). By moving from a lecture to a co-constructivist or critical pedagogy, we can transform students from passive, docile learners into "critical co-investigators in dialogue with the teacher" (Freire, 1970, p. 62), which might help students challenge power dynamics elsewhere. 
In order for SICPs, and HE educators generally, to teach the way they want, they need more control over what and how they teach, something that seems to be slipping out of grasp with the increasing reliance on student satisfaction and the TEF. For example, in research on educators' perceptions of effective teaching in HE, Carnell (2007) found that although most participants indicated a preference for co-constructivist pedagogies that relied on dialogue and a more equal power dynamic between teachers and students, performativity affected educators' ability to teach effectively, specifically a disconnect between the expectations of students and teachers and how that played out in the classroom. This suggests that student expectations, and whether they are met, are becoming increasingly influential in dictating the practice of educators in $\mathrm{HE}$, meaning that involving students in shaping their learning experience may be more important than ever before. By engaging students in critical dialogue about what they are learning, how it connects with their lived experience, and how they can challenge taken for granted assumptions about knowledge and society, we position students as 'critical' consumers in HE that can use their voice to challenge and shape the way HE itself is approached. 


\section{References}

Aronowitz, S and Giroux, H 1985. Radical education and transformative intellectuals. CTheory, 9, 48-63.

Carnell, E 2007. Conceptions of effective teaching in higher education: extending the boundaries, Teaching in Higher Education, 12:1, 25-40.

Barnett, R 1990. The Idea of Higher Education, Buckingham, SRHE.

Barnett, R 1994. The Limits of Competence, Buckingham, SRHE.

Biesta, G 2010. Good Education in an Age of Measurement, Boulder, Paradigm.

Breunig, M 2009. Teaching for and about critical pedagogy in the post-secondary classroom. Studies in Social Justice, 3, 247-262.

Department for Business, Innovation and Skills 2011. Higher education: Students at the heart of the system.

Freire, P 1970. Pedagogy of the Oppressed, London, Continuum.

Lea, S J, Stephenson, D and Troy, J 2003. Higher Education Students' Attitudes to Student Centred Learning: Beyond 'educational bulimia'. Studies in Higher Education 28(3), 321-334.

O'Neill, G. and McMahon, T. (2005) Student-centred learning: What does it mean for students and lecturers. In: Emerging issues in the practice of university learning and teaching I. Dublin: AISHE.

Schugurensky, D., 2014. Paulo Freire. Bloomsbury Publishing.

Webster, RS 2015. In defence of the lecture. Journal of Teacher Education, 40, 88-105. 